\title{
Die Privatscheidung im deutschen und gemeinschaftsrechtlichen Internationalen Privat- und Verfahrensrecht
}

\author{
Außergerichtliche Ehescheidungen im Spannungsfeld von kultureller Diversität \\ und Integration
}

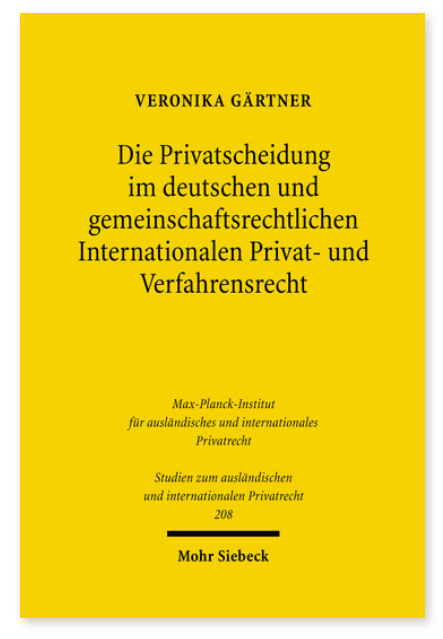

2008. XXV, 486 Seiten. StudIPR 208

ISBN 978-3-16-151393-0

DOI 10.1628/978-3-16-151393-0

eBook PDF 104,00€

ISBN 978-3-16-149806-0

fadengeheftete Broschur 104,00€
Das Familienrecht, und damit auch das Eherecht, ist in starkem Maße in der Kultur des jeweiligen Rechtssystems verwurzelt. Im Falle internationaler Sachverhalte treten Kollisionen dann besonders deutlich zu Tage, wenn eine der beteiligten Rechtsordnungen die Ehescheidung - anders als das deutsche Recht - nicht staatlichen Gerichten, sondern den Ehegatten selbst oder aber religiösen Instanzen anvertraut. Sogenannte Privatscheidungen stellen das Recht sowohl in inhaltlicher wie auch in methodischer Hinsicht vor schwierige Herausforderungen.

Veronika Gärtner widmet sich den durch die Privatscheidung aufgeworfenen Fragen sowohl auf nationaler als auch auf gemeinschaftsrechtlicher Ebene, wobei sie hier insbesondere mögliche Auswirkungen der Entwicklungen im Gemeinschaftsrecht auf die Behandlung von Privatscheidungen untersucht. Im Mittelpunkt der Betrachtung steht der grundsätzliche Konflikt zwischen dem durch Mobilität und Globalisierung verstärkten Bewusstsein für Diversität auf der einen und der Regionalisierung durch Europäisierung auf der anderen Seite. Letztere führt im Bereich des Internationalen Privatrechts zu einem Methodenwechsel in Form des Anerkennungsprinzips, und damit zu einer Verdrängung des klassischen Internationalen Privatrechts. Die Autorin untersucht diese Entwicklung im Hinblick auf die Privatscheidung und zeigt, dass das gemeinschaftsrechtliche Internationale Privatrecht das klassische Internationale Privatrecht nicht in allen Bereichen abzulösen vermag.

Veronika Gärtner Geboren 1979; Studium der Rechtswissenschaft in Heidelberg und Aberdeen/Schottland (LL.M. International and European Law); 2006-2007 wissenschaftliche Mitarbeiterin am Institut für ausländisches und internationales Privat- und Wirtschaftsrecht, Universität Heidelberg; 2008 Promotion; Rechtsreferendarin am LG Kiel.

Jetzt bestellen:

https://mohrsiebeck.com/buch/die-privatscheidung-im-deutschen-und-gemeinschaftsrechtlichen-internationalen-privat-undverfahrensrecht-9783161513930?no_cache=1

order@mohrsiebeck.com

Telefon: +49 (0)7071-923-17

Telefax: +49 (0)7071-51104 